\title{
Change of attitude? A diachronic study of stance
}

\begin{abstract}
Stance, or the writer's expression of personal attitudes and assessments of the status of knowledge in a text, has been a topic of interest to researchers of written communication for the last three decades. Notwithstanding this interest, and a more general curiosity concerning the gradual evolution of genres, very little is known of how stance in academic writing has changed in recent years and whether such changes have occurred uniformly across disciplines. Drawing on a corpus of 2.2 million words taken from the top five journals in each of four disciplines at three distinct time periods, we seek to determine whether authorial projection has changed in academic writing over the past 50 years. Our paper presents, and attempt to account for, some surprising variations and an overall decline in explicit stance during this period.
\end{abstract}

Successful research writers construct texts by taking a novel point of view towards the issues they discuss while anticipating readers' imagined reactions to those views. This intersubjective positioning is encompassed by the term stance and, in various guises, has been a topic of interest to researchers of written communication and applied linguists for the last three decades. Recognising that academic writing is less objective and "author evacuated" than Geertz (1988) and others once supposed, analysts have sought to identify the ways that writers use language to acknowledge and construct social relations as they negotiate agreement of their interpretations of data with readers. Despite prolonged and widespread curiosity concerning the notion of stance, however, together with an interest in the gradual evolution of research genres more generally, very little is known of how it has changed in recent years and whether such changes have occurred uniformly across disciplines. In this paper we set out to explore these issues. Drawing on a corpus of 2.2 million words 
taken from the top five journals in each of four disciplines at three distinct time periods, we seek to determine whether authorial projection has changed in academic writing over the past 50 years.

\section{Conceptions of stance}

The ways that writers and speakers express their opinions is an important feature of all interaction and researchers have long been concerned with describing how stance is linguistically marked. A range of terms have been used to conceptualise the idea. Some are umbrella conceptions such as posture (Grabe 1984), attitude (Halliday, 2004), appraisal (Martin, 2000), evaluation (Hunston \& Thompson, 2000) and metadiscourse (Hyland, 2005a). Others focus more specifically on the linguistic realisations of judgements, feelings, or viewpoints by looking at intensity (Labov 1984), disjuncts (Quirk et al, 1985), hedges (Hyland, 1998) and modality (Palmer, 1986).

Two related ideas have been particularly influential in current conceptions of stance: evidentiality (Chafe, 1986; Chafe and Nichols, 1986) and affect (Ochs and Schieffelin, 1989; Besnier, 1990). Evidentiality refers to the status of the knowledge contained in propositions and concerns its reliability, implying its source, how it was acquired and the credibility we can invest in it (eg Chafe, 1986). In contrast, the term affect is used "to include feelings, moods, dispositions, and attitudes associated with persons and/or situations" (Ochs and Schieffelin, 1989:7). So, affect markers express the intensity and particularity of personal feelings and attitudes rather than evaluations of knowledge. Most discussions of stance seek to combine these two elements into a single model. Thus, Biber and Finegan (1989), for example, identified how this is expressed in various spoken and written genres while Martin's model of appraisal lists the possible realisations of attitudinal stance meanings as indicating affect (emotional responses), judgment (moral evaluations), and appreciation (aesthetic evaluations) while engagement aligns broadly with epistemic stance meanings (Martin 2000; Martin and White 2005).

Another recent approach to stance stresses its evaluative aspects (e.g. Hunston \& Thompson, 2000; Hunston, 1994), seeking to unpack the judgements writers make in expressing a position on what 
they discuss. Hunston and Thompson (2000: 22-26), for example, suggest four main dimensions of evaluative language which can convey a writer's stance:

1. Value - or variations along a good-bad scale

2. Status -relating to the degree of certainty the speaker/writer invests in information

3. Expectedness - referring to how obvious or expected the information is to the hearer/reader

4. Relevance - judgements of significance or relevance to the listener/reader

Finally, considerable work has been done under the umbrella of metadiscourse, or linguistic material referring to the evolving text and to the writer and imagined reader of that text. Hyland's work has been influential here, distinguishing interactional and interactive types, broadly, language which conveys the attitudes of writers to their material and readers, and that used to create a more accessible and persuasive text (Hyland, 2005a).

All of these approaches are based on a view of writing (and speaking) as social engagement and attempt to reveal the ways writers project themselves into their discourse to signal their attitudes towards the content of their talk. In addition, all draw on a distinction between meanings that indicate a speaker/writer's personal attitudes and assessments, and those which comment on the truth of a proposition. In line with Biber (2006) and Hyland (2005b) we see stance as the writer's expression of personal attitudes and assessments of the status of knowledge in a text and in the next section we discuss the relevance of these meanings to academic writing.

\section{Stance in academic writing}

First, we need to acknowledge that overt stance expressions are far less common in academic prose than in other registers (e.g. Gray \& Biber, 2012). Biber and Finegan's (1989) cluster analysis of 12 lexico-grammatical stance devices, for example, statistically categorized $75 \%$ of the written academic texts as 'faceless'. Biber (2006) found that spoken registers are more heavily stance-laden, even in academic contexts and Hood (2010), using an Appraisal model, found little affect in research texts. As a result, and until fairly recently, much of the research into stance tended to concentrate on mass audience texts, such as journalism, politics, and media discourses, which seemed most likely to yield a richer harvest of explicitly author- avowed positions. 
We also need to grant that stance, like other features of disciplinary discourses, are not static and unchanging markers of professional research writing. A considerable literature has addressed the emergent nature of the article genre (e.g. Bazerman, 1984). Thus Atkinson(1999), for example, has tracked changes in papers published in The Philosophical Transactions between1675 to 1975, finding a relentless growth in 'informational' features until the latter date, a change which Atkinson describes as a move from a less 'author-centred' rhetoric to a highly abstract and 'object-centred one'. The genre has also seen a decline in the frequency of be-passives compared with transitive actives through the $20^{\text {th }}$ century (Seone, 2013) and a movement towards more compressed, phrasal expressions over elaborated, clausal expressions which allow for faster, more efficient processing by expert readers ( Biber \& Grey, 2016). Academic genres, however, appear to change only slowly so that Hundt and Mair (1999: 221) suggest that they reside at the more conservative end of "a cline of openness to innovation ranging from 'agile' to 'uptight' genres".

We know little about changes in the expression and frequency of stance features however, although it essential to recognise the importance of authorial-investment in research texts. Successful academic writing depends on the individual writer projecting a personal assessment of research entities and claims, although this needs to be done within a shared professional context. In claiming a right to be heard, and to have their work taken seriously, writers must simultaneously take a stance towards what they discuss and display competence as disciplinary insiders. This competence is, at least in part, achieved through writers constructing a dialogue with readers which situates both their research and themselves. This is crucial in establishing community-approved interactions and highlights the centrality of authorial 'positioning': adopting a point of view in relation to both the issues discussed in a text and to others who hold points of view on those issues (Hyland, 2012; 2015). Stance in this sense is a consistent series of rhetorical choices which allow authors to conduct interpersonal negotiations and balance claims for the significance, originality and plausibility of their work against the convictions and expectations of their readers.

Considerable research interest has therefore been invested in discovering precisely how writers persuade readers of their claims and lead the academic community to "adjust its network of con- 
sensual knowledge in order to accommodate those claims' (Hunston, 1994: 192). Studies have shown the lexical and grammatical choices which seem most productive expressions of stance in academic genres such as undergraduate essays (Aull \& Lancaster, 2014), theses (Charles, 2006), abstracts (Hyland and Tse , 2005) and research articles (Hyland, 2012) as well as in L2 student writing (Hyland, 2004) and in disciplines as diverse as Geology (Dressen, 2003) and art-history (Tucker, 2003). Stance is also a key feature of readers' assessments of text quality. In an interview study, for example, Lancaster (2014) found that tutors judgements of 'critical reasoning and analytic rigor in argument papers by economics students were influenced by valued configurations of stance while Uccelli et al (2013) discovered that hedges functioning as an epistemic stance marker significantly predicted assessments of writing quality in the essays of high school students.

An important consideration here is that stance is always expressed in relation to some set of expectations so that personal judgements are only convincing, or even meaningful, when they contribute to and connect with a communal ideology or value system concerning what is taken to be interesting, relevant, novel, useful, good, and so on. Writers' stance options, in other words, are not made from an infinite range of alternatives, but from a restricted sub-set of options which reveal how they understand their communities thorough the assumptions their stances encode. Readers can always refute claims and this gives them an active and constitutive role in how writers construct their arguments. Thus any successfully published research paper anticipates a reader's response and itself responds to a larger discourse already in progress. Stance choices are, in other words, disciplinary practices as much as individual positions.

Because writers comment on their propositions and shape their texts to the expectations of different audiences, the expression of stance varies according to discipline. In the next section we will outline our corpus and approach and then go on to explore whether authors' use of stance features has changed over time.

\section{Corpus, model and method}

We created three corpora taking research articles from the same five journals in four disciplines spaced at three periods over the past 50 years: 1965, 1985 and 2015. The different time spans were 
chosen to see if any changes were more pronounced in the later or earlier period, although we were concerned with overall changes over the 50 years. Applied linguistics, sociology, electrical engineering and biology were selected as representative of both the soft applied fields and the hard sciences, and we took six papers at random from each of the five journals which had achieved the top ranking in their field according to the 5 year impact factor in $2015^{1}$. The journals are listed in Appendix 1 and together the corpus comprised 360 papers of 2.2 million words as shown in Table 1 . This indicates the huge increase in the length of articles over this period:

Table 1: Corpus size and composition

\begin{tabular}{lcccc}
\hline Discipline & $\mathbf{1 9 6 5}$ & $\mathbf{1 9 8 5}$ & $\mathbf{2 0 1 5}$ & Overall \\
Applied linguistics & 110,832 & 144,859 & 237,452 & 493,143 \\
Biology & 244,706 & 263,465 & 237,998 & 746,169 \\
Engineering & 92,062 & 97,545, & 235,681 & 425,288 \\
Sociology & 149,788 & 196,232 & 262,203 & 608,223 \\
& & & & \\
Totals & 597,388 & 604,556 & 973,334 & $2,272,823$ \\
\hline
\end{tabular}

The corpora were then searched for stance features using the concordance software AntConc

(Anthony, 2011). In this paper we follow Hyland's (2005b) approach to stance in academic writing which regards it as

writer-oriented features of interaction and refers to the ways academics annotate their texts to comment on the possible accuracy or credibility of a claim, the extent they want to commit themselves to it, or the attitude they want to convey to an entity, a proposition, or the reader. (Hyland, 2005b: 178)

While this comprises only half of Hyland's model of intersubjective positioning, it would be hard to also do justice to engagement in a single paper. The notion of stance, however, represents a coherent concept and body of research which is worth discussing in its own right. This framework encompasses three main components: evidentiality, affect and presence.

- Evidentiality - the writer's stated commitment to the reliability of the propositions he or she presents and their potential impact on the reader, expressed through hedges and boosters

- Affect - a broad range of personal and professional attitudes towards what is said expressed through attitude markers

\footnotetext{
${ }^{1}$ Two journals, TESOL Quarterly and Foreign Language Annals only began in 1967 and so papers were chosen from issues in that year. $C C C$ is the only one not ssci-indexed but it is an influential, long running journal listed in the language \& linguistics subcategory of Arts \& Humanities Thomson Reuters citation index.
} 
- Presence - concerns the extent to which the writer chooses to intrude into a text through the use of first person pronouns and possessive determiners.

Hyland's model recognises the role that readers play in shaping a writer's stance by understanding texts as community negotiated processes so that these projected reader positions help establish "a virtual dialogue" (Hyland, 2012). Stance is socially inscribed in academic writing as these shared practices align claims with existing knowledge and sanction what ideas will be legitimated. It therefor allows us to study disciplinary variations. Overall we examined 140 different items, taken from the appendix of Hyland (2005a), searching for both US and British spellings, and manually examined and counted each concordance to establish that the feature was performing a stance function (e.g. only cases of exclusive we). Working independently, a $10 \%$ sample was coded by both authors to ensure reliability with $95 \%$ agreement .

\section{Changing patterns of Stance}

Our analysis of these features shows a steady increase in authorial stance in academic writing over the past 50 years, with a massive $54 \%$ rise in raw numbers. When adjusted for the large rise in the length of papers, however, we see a small, but significant, decrease in the expression of stance, as shown in Table 2. The normed figures show that the increase in published words is accompanied by a substantial dip in authors' explicit stance choices until 1985 and then a slight rise once again to the present.

Table 2: Distribution of stance features over time

\begin{tabular}{lllll}
\hline & $\mathbf{1 9 6 5}$ & $\mathbf{1 9 8 5}$ & $\mathbf{2 0 1 5}$ & \% change \\
Total stance items & 19,372 & 20,465 & 29,783 & $53.7 \%$ \\
Per 10,000 words & 324.3 & 291.6 & 304.9 & $-6.0 \%$ \\
& & & & \\
\hline
\end{tabular}

This overall relative decline in stance features turns out to be not evenly distributed across all fields but indicates changing argument patterns in different disciplines. Table 3 shows that despite large increases in the use of explicit stance features in applied linguistics and sociology over the period, writers in these disciplines now position themselves less obtrusively than 50 years ago. Biologists have adopted a slightly more visible presence, but engineers appear to be moving towards a very different stance profile. 
Table 3 Changes in stance frequencies over time by discipline (raw numbers \& per 10,000 words)

\begin{tabular}{lllll}
\hline Discipline & $\mathbf{1 9 6 5}$ & $\mathbf{1 9 8 5}$ & $\mathbf{2 0 1 5}$ & \% change \\
Applied ling & $4934(351.2)$ & $5434(375.4)$ & $7009(295.2)$ & $42.1 \% \quad(-16.0 \%)$ \\
Sociology & $5656(377.6)$ & $6084(301.0)$ & $8493(323.9)$ & $50.2 \% \quad(-14.3 \%)$ \\
Electrical eng & $2561(262.4)$ & $2905(283.4)$ & $7632(323.6)$ & $198.0 \%(23.3 \%)$ \\
Biology & $6221(254.2)$ & $6039(229.3)$ & $6649(275.4)$ & $6.9 \% \quad(8.3 \%)$ \\
& & & &
\end{tabular}

We have to admit that these trends were completely unexpected. The attention given to stance and interpersonal positioning more generally might convey an impression that academic writing is now more personally engaging. Our results, at least in the social sciences, however, suggest the opposite: that the additional word limits allocated to authors to discursively explore issuers has not been matched with an equivalent degree of personal intrusion and evaluation. Biologists have slightly increased their use of stance features, although this is almost entirely due to a massive $150 \%$ increase in self-mention since 1985. Most intriguingly, and surprisingly, is the upsurge in the frequency of stance features in electrical engineering, which in contrast to all other disciplines, showed an increase in all four features examined.

We discuss these changes in more detail below, but there seems to have been a significant shift in how these disciplines understand academic argument and the ways their members seek to persuade peers. Obviously, presenting a self is central to the writing process (Ivanic 1998), and we cannot avoid projecting an impression of ourselves and how we stand in relation to our arguments, discipline and readers (Hyland, 2004). Writers cannot, in other words, not take a stance, whether this is a confident and assertive author, a tentative interpreter or a modest scientist, carefully hiding behind empirical findings or flawless logical deduction. There is no 'faceless' writing and all stance choices are important rhetorical decisions that affect how the message is received and the ways readers react to a text. But while writers in different disciplines represent themselves, their work and their readers in very different ways, with those in the humanities and social sciences tending to take more personal positions than those in the sciences and engineering, this seems to be changing. 
The soft knowledge fields, particularly in the past 30 years in the case of applied linguistics, have been slowly moving towards more 'author-evacuated' prose; increasingly mimicking hard science practices. Speculatively this might be attributed to an increase in more empirically grounded and quantitative studies which restrict opportunities for more extensive overt stance-taking. On the other hand, writers in the hard sciences in our sample, and spectacularly in the case of electrical engineering, seem to be edging towards greater visibility, especially through self-mention to create a more evident presence in the text. In the following two sections we will explore these results in greater detail by looking at the main components of stance: evidentiality, affect and presence.

\section{Shifting commitment and increasing presence - what changes and to what extent?}

Table 4 shows that stance features are not changing in a single direction nor behaving in uniform ways, either across times or disciplines. It indicates rises in hedges in engineering and biology, falls in the use of boosters by all disciplines but engineering, relatively steady uses of attitude markers and, excepting applied linguistics, substantial rises in self-mention.

Table 4: Changes in stance features by discipline (per 10,000 words)

\begin{tabular}{lccc|ccc|cccc|ccc}
\hline & \multicolumn{4}{c}{ Applied Ling } & \multicolumn{4}{c}{ Sociology } & \multicolumn{3}{c}{ Electrical } & \multicolumn{3}{c}{ Biology } \\
Feature & $\mathbf{1 9 6 5}$ & $\mathbf{1 9 8 5}$ & $\mathbf{2 0 1 5}$ & $\mathbf{1 9 6 5}$ & $\mathbf{1 9 8 5}$ & $\mathbf{2 0 1 5}$ & $\mathbf{1 9 6 5}$ & $\mathbf{1 9 8 5}$ & $\mathbf{2 0 1 5}$ & $\mathbf{1 9 6 5}$ & $\mathbf{1 9 8 5}$ & $\mathbf{2 0 1 5}$ \\
\hline Hedges & 201.1 & 169.4 & 128.6 & 187.8 & 148.2 & 148.7 & 117.5 & 122.5 & 126.4 & 130.2 & 132.9 & 148.4 \\
& & & & & & & & & & & & \\
Boosters & 107.7 & 79.7 & 67.0 & 88.8 & 62.7 & 57.3 & 82.6 & 87.3 & 95.0 & 76.3 & 51.9 & 51.7 \\
$\begin{array}{l}\text { Attitude } \\
\text { markers }\end{array}$ & 42.3 & 38.5 & 31.2 & 35.7 & 32.0 & 28.0 & 9.5 & 8.5 & 16.4 & 27.9 & 24.3 & 27.2 \\
$\begin{array}{l}\text { Self- } \\
\text { mention }\end{array}$ & 94.0 & 87.8 & 68.4 & 65.3 & 67.1 & 89.9 & 52.8 & 65.1 & 85.8 & 19.8 & 20.2 & 52.1
\end{tabular}

Overall, it appears that, over time, the biologists have become more measured in their stance expression and also more "present" in terms of self mentions, intervening more overtly as writers. The electrical engineers are, in general, taking a stronger stance, increasing their expression of attitude, presence, and evidentiality. In contrast, while the sociologists are becoming increasingly "present" in terms of self mentions, they are expressing attitude and epistemic judgments less frequently, ). The applied linguists are becoming increasingly faceless overall, a directly opposite trend to that we see in the engineering texts. We will look at the changes in stance features in more detail below. 


\section{Evidentiality}

Evidentiality refers to epistemic aspects of stance and includes meanings of certainty, doubt, actuality, precision or limitation. Gray and Biber (2012) point to the prevalence of these stance meanings in all academic genres, regardless of mode and much has been written on their use in academic writing (e.g. Hyland, 1998; Biber, 2006). These assessments of certainty allow authors to express statements from a particular perspective. They are realized grammatically, through clauses (e.g. as we all know, it is doubtful that...), lexically through words like definitely, might, likely, etc. and by phrasal forms (seems obvious that, may be due to). Hedges are often a prudent option for authors, allowing them to open a discursive space and mark statements as provisional to involve readers as participants in their ratification while conveying respect for colleagues' views. Boosters, on the other hand, express conviction; seeking to assert claims categorically and shut down alternative voices (Hyland, 1999).

These then, are devices which either invest statements with the confidence of factual reliability or withhold complete commitment to imply that a claim is based on the author's plausible reasoning rather than certain knowledge. Both options represent an author's explicit intrusion into a text to convey a personal stance. Because all statements are evaluated and interpreted through a prism of disciplinary assumptions, writers must calculate what weight to give to an assertion, attesting to the degree of precision or reliability that they feel able to invest in it. This means that we see variations across time and disciplines.

Interestingly, both applied linguistics and sociology recorded dramatic falls in the use of hedges and boosters over this 50 year period (when normed for the increase in corpus size). Hedges fell $36 \%$ per 10,000 words in applied linguistics and $21 \%$ in sociology, and boosters were down $38 \%$ and 35\% respectively. May and would remain the most frequently used hedges in both disciplines but their combined frequencies per 10,000 words fell by almost $50 \%$ over the period and the other modal hedges also declined. May, would, should, could and might represented $40 \%$ of all hedges in sociology and 48\% in applied linguistics in 1965 and 34\% and 34\% respectively in 2015 while suggest and likely were the only forms to become more common among the most frequent hedges. This seems to represent not only a decline in hedging but a shift away from forms which, according 
to Coates (1983), express assumption (should and ought), possibilities (may, might and could) and hypotheticality (would) towards those which carry more speculative judgements, predicated on a reference to the uncertainty of human evaluation.

Boosters have also steadily declined in both soft knowledge disciplines and also shown a trend towards more verbal uses. The most common form in 1965 and 1985 in both applied linguistics and sociology was must, the predominant modal of inferential certainty, but this had disappeared from the top 20 by 2015. Cognitive verbs such as think, believe and know have also declined while show, demonstrate and find have all increased. Although cognitive verbs can function as either hedges or boosters, their decline as boosters in favour of more objective choices suggest a move from personal beliefs towards more empirical and data-supported commitments to claims:

(3) That, I believe must be sought in an unhappy confusion in the minds of the teachers of composition. [Applied linguistics, 1965]

(4) Let me say at once that I think these main tenets are indisputable, and that they have had a tremendous impact on linguistics. [Applied linguistics, 1965]

(5) We demonstrate that this inconsistency has resulted from inadequate control, ... including the basis of norm comparisons. [Applied linguistics, 2015]

(6) In summary, we find that females are markedly superior to males in recalling social network information.

[Sociology, 2015]

In the sciences, evidential changes have surprisingly moved in the opposite direction. Hedging increased in both fields we studied, albeit only marginally, rising 14\% (per 10,000 words) in biology and $8 \%$ in electronic engineering, with may remaining the preferred form for both fields throughout. This expresses greater certainty than might and indicates a 50-50 assessment of possibilities, but also facilitates a certain ambiguity between enabling circumstances which permit $X$ ('it is possible for $\mathrm{x}$ ') and the writer's lack of confidence in the possibility that $X$ ('it is possible that $\mathrm{x}$ '). The fuzziness allows writers to hedge a hedge. Frequencies of this form, however, declined in both fields, as did those for would and should, as well as approximation words such as about, estimate and approximately, perhaps indicating greater precision in measurements. Could, which is similar 
in meaning to may in expressing tentative possibility, gained increasing popularity through the period, pointing to cautious interpretations instead of hypothesising or exploring assumptions.

While engineering and biology displayed broadly similar trends with hedges, they diverged considerably in the use of boosters, with biology following the pattern of the social science disciplines and recording a $32 \%$ fall and engineering increasing its use of boosters by $15 \%$. Show, must and know were the preferred forms in both disciplines throughout although engineers came to use a much wider array of expressions as the period wore on, especially establish, prove and clearly. These are forms which are used to ensure readers are aware of the strength of results or the claims being made:

(7) We have established above that $(e(i)(t), \omega(i)(t))$ are bounded for all $i=1, \ldots, j$.

[Engineering, 2015]

(8) Our contribution here will be to prove this conjecture:

Theorem 1.3. There exists a regular function $\mathrm{X} 0:[0,1] \rightarrow \mathrm{R}$ such that, if the sequence $(x t) t N$ is defined according to (1.3), then $x t(1)-x t(0)>2$ for all $t$.

[Engineering, 2015]

(9) Clearly, the control action has significant impact on the variance of the temperature.

[Engineering, 2015]

In summary, authors in the soft knowledge fields in our corpus have exhibited a movement towards considerably less marking of evidentiality over the last 50 years. It seems that research is being reported more categorically in these disciplines without the authors annotating their statements for either truth or precision. We also find changes in the most common forms themselves, with less modals and more verbal choices and a trend towards more empirically-oriented boosters. In the sciences, on the other hand, there is greater circumspection in the use of hedges, although with a growing tendency to blur personal judgements and enabling possibilities and to hedge quantities rather than interpretations. Both weaken the stance taken. Engineering was the only discipline to see an increase in boosters, using them to underline the strength of results rather than subjective interpretations of them. Together these changes represent a substantial shift to more cautious and author- 
evacuated positions in the soft knowledge fields and a growing tendency for authors in the sciences to express their results with greater visibility.

\section{Affect}

Attitudinal stance indicates the writer's affective, rather than epistemic perspectives and includes evaluations and personal feelings as he or she comments on the material under discussion (interestingly, surprisingly) or on the communication itself (e.g. honestly, in truth). While attitude is expressed throughout a text by the use of subordination, comparatives, progressive particles, punctuation, text location, and so on, it is most explicitly signalled by attitude markers such as attitude verbs (eg. agree, prefer), sentence adverbs (unfortunately, hopefully), and adjectives (appropriate, logical). The emphatic expression of affect is relatively infrequent in academic research writing (Biber et al, 1999; Hyland, 2004) and tends to be implicitly invoked rather than openly inscribed (Martin \& White, 2005). Attitude markers thus bring affect to the surface through forms with positive or negative meanings, as in these examples:

(10) These results were surprising in that they showed that a Ca2+ influx apparently is not required for a low level of increase in the rate of transcription...

(11) Student A2 presented another fascinating case study in that he had serious difficulties expressing himself in written English.

By signalling an assumption of shared attitudes and reactions to material, writers both express a position and seek to bring readers into agreement with it.

In our longitudinal data we find an overall decline in the explicit marking of affect with fairly dramatic falls in the soft sciences and, once again, an increase in electronic engineering. In fact, the patterns we observe in attitude markers closely mirror those for hedges and boosters discussed above. Over the 50 year span, frequencies fell by $26 \%$ in applied linguistics and by $22 \%$ in sociology (normed to 10000 words), remained almost unchanged biology and, admittedly with very small raw numbers, rose by $73 \%$ in engineering. 
The items important and restrictive even remained the top two choices across all four fields, although their frequencies fell in all disciplines. Both these forms enable writers not only to express a stance towards something but also to align that stance with the interests of their community. Crafting texts which offers a positive evaluation of a result or entity assumed to be valued by readers also has the added value of making it difficult to challenge:

(12) The cutoff frequency is important for analysing bandwidth of small-signal amplifiers and power gain of power amplifiers.

(13) One important feature which differentiates authentic lecture discourse from written text or scripted lectures is the way they are structured at the micro-level.

By categorically asserting statements which assume shared attitudes the writer constructs a relationship along with a text, but this is a relationship where the writer is firmly in the driving seat.

Similarly, even conveys an attitude by focusing attention on the author's assessment of the relative unexpectedness of something being the case, while implicitly drawing on shared knowledge to do so, as here:

(14) Aflagellate cells maintained in CdCI2 did not regrow flagella, even after a $24 \mathrm{~h}$ period.

(15) Even Ralph Dahrendorf considered the Nazi regime as 'specific' and 'unique'.

(Soc)

The biologist in (14) takes a stance which squarely positions him with the views of knowledgeable peers who are likely to be equally surprised at this result. In (15) the sociologist positions himself in proximity with an informed audience by drawing on their shared knowledge of the great social thinker's views of enforced constraint the ways groups are controlled by a hierarchy of authority and power. In both cases a clear stance is expressed towards both the topic and the audience.

Other items among the most preferred expressions of attitudinal stance across all disciplines are expected and interesting, which generally comment on data or the results being presented:

(16) As expected from the border analysis, the unstable H59 line contained a single intact copy of T-DNA. 
(17) We expected the group with more exposure to the target words in natural context through in-class activities to perform better on the posttest.

(18) In particular, it is interesting to observe that the travel time efficiency advantage of the $25 \% 150 \%$ layout relative to random storage is almost completely obscured by excessive waiting times.

(19) When the distribution of data was examined by a branch of the legal profession, some interesting differences were found...

Once again, what might be considered interesting or anticipated is likely to be shared by one's peers, the informed insiders who inhabit the same community and contribute to its research and discourses.

One high frequency item marking attitudinal stance which is more discipline specific is essential, which occurs far more commonly in the hard sciences. While the adverbial form essentially is often used as a hedge, essential underlines the author's assessments regarding the contribution or component of an entity or process. It is a stance expressing the author's view that something is vital to a situation or activity (20) or a fundamental part of the nature of something (21):

(20) ... openness to strangers, and acceptance of differences are essential in establishing urban communal life.

(21) Guessing, top-down processing, and inferencing are all essential aspects of effective communication

Interestingly, the two hard science disciplines we studied use essential in broadly different ways. Engineers overwhelmingly use the form as a predicative adjective, either characterizing the nominal expression in subject position (22) or, less commonly, following a direct object (23):

(22) System modelling and experimentation are essential parts of the engineering discipline.

(23) For control systems to be able to adapt to a variety of unexpected changes, dynamic learning is essential. 
In all cases, the author gives an evaluation of the material he or she is presenting, marking a clear stance towards its perceived value.

Although this pattern is also common in biology, authors here tend to make far greater use of structures with an extraposed to-clause or followed by for, with the latter twice as frequent in the 2015 corpus. While both forms express judgments of extreme importance or necessity and are generally considered interchangeable when preceding a noun phrase, essential to seems to convey a stronger meaning of essence or inherent quality. Thus in (24) connection the author posits might be seen as intrinsic to the plant's development and so seeks to establish a stronger relationship than that in (25), which might only be a necessary factor.

(24) The continued delivery of ions via the transpiration stream ensures that the leaf is supplied with the mineral nutrients essential to its growth and development.

(25) Therefore, the crs 1 gene is essential for the biogenesis of the ATP synthase complex.

The stronger meaning of essential to is more common in our corpus and seems to be increasing, conveying a stronger authorial stance. In all uses of essential, however, as in many other markers of affect, there is no explicit attribution of the stance to the author, but this overt positioning can easily be inferred.

To sum up the changes we have observed in the use of affective stance in these four disciplines, we can say that they closely reflect those observed for epistemic markers. Normed frequencies for the explicit marking of attitude have seen large increases in engineering, declines in applied linguistics and sociology, and biology virtually unchanged. Once again, it is difficult to account for these changes, but it appears that over the past 50 years there has been a broad movement towards homogenization of stance in academic writing, with authors in the soft sciences being more prudent in their expressions of attitude and scientists becoming less so. However, while the sciences have increased both the frequency and range of the markers they use to convey affect, the most common items remain those which refer to judgements of importance and expectation rather than emotion. They are also items which seek to closely align writers with a disciplinary value system. 


\section{Presence}

A writer can present a more or less visible stance by choosing to step into a text through selfmention or to use impersonal forms. How we understand writers and their attitudes to their arguments and readers is heavily influenced by their choices of authorial presence and this, in turn, typically reflects disciplinary practices. In the sciences it is common for writers to downplay their personal role to highlight the phenomena under study, the replicability of research activities, and the generality of the findings, subordinating their own voice to that of unmediated nature. Such a strategy subtly conveys an empiricist ideology that suggests research outcomes would be the same irrespective of the individual conducting it. In the humanities and social sciences, in contrast, the use of the first person is closely related to the desire to both strongly identify oneself with a particular argument and to gain credit for an individual view.

Table 4 above shows that authorial self-mention has undergone the greatest changes of all stance categories over the last 50 years. Frequencies have increased 38\% in sociology (per 10,000 words), $63 \%$ in electrical engineering and a massive $163 \%$ in biology, while declining by $27 \%$ in applied linguistics. Again, these results, and especially those for biology and applied linguistics, defy our expectations, with the biggest increases in the hard sciences. Table 5 shows that the most dramatic changes have occurred since 1985 and that the patterns of change have been uneven, with $I$ replacing we as the preferred marker in applied linguistics, for example, and $I$ becoming more common in sociology after a fall in the middle of the period.

Table 5: Changes in self-mention by discipline (per 10,000 words)

\begin{tabular}{|c|c|c|c|c|c|c|c|c|c|c|c|c|}
\hline \multirow[b]{2}{*}{ Feature } & \multicolumn{3}{|c|}{ Applied Ling } & \multicolumn{2}{|c|}{ Sociology } & \multicolumn{4}{|c|}{ Electrical } & \multicolumn{3}{|c|}{ Biology } \\
\hline & 1965 & 1985 & 2015 & 1965 & 1985 & 2015 & 1965 & 1985 & 2015 & 1965 & 1985 & 2015 \\
\hline we & 42.8 & 42.9 & 29.5 & 33.6 & 29.9 & 40.2 & 47.1 & 65.1 & 71.0 & 10.1 & 12.3 & 37.9 \\
\hline I & 22.1 & 15.8 & 29.5 & 12.8 & 9.3 & 28.7 & 0.1 & 0.2 & 0.5 & 2.2 & 1.7 & 1.8 \\
\hline our & 16.2 & 19.1 & 8.9 & 12.8 & 15.8 & 12.9 & 3.6 & 4.1 & 6.9 & 5.8 & 4.1 & 10.1 \\
\hline us & 5.7 & 6.6 & 3.2 & 3.9 & 2.9 & 4.0 & 1.8 & 3.9 & 7.2 & 1.2 & 0.8 & 1.8 \\
\hline Other & 7.2 & 3.4 & 4.1 & 1.3 & 1.3 & 8.0 & 0.0 & 0.0 & 0.1 & 0.6 & 0.4 & 0.4 \\
\hline Totals & 94.0 & 87.8 & 68.4 & 65.3 & 67.1 & 89.9 & 52.8 & 65.1 & 85.8 & 19.8 & 20.2 & 52.1 \\
\hline
\end{tabular}


It is obviously much harder to explain these trends than to describe them. While scientific writing remains the prototypical exemplar for representing meanings in an objective and formal way, subordinating the authority of the individual to the authority of the text, authors in the sciences are increasing their presence in the text with far greater willingness than in the past.

This increase, however, is confined to plural forms, which allow authors to create more distance between themselves and their reporting than first person and so temper a more invasive stance. It is nevertheless a significant trend. One reason for it may be the need for scientists to respond to the imperative of "impact" as a measure in annual performance reviews and career assessments, making their work less impersonal and more accessible to audiences in the commercial world outside the university. More likely, however, a more visible presence is a way of ensuring that their individual interpretations and claims do not go unnoticed by those same university human resource panels where applications for jobs, tenure and promotion are judged. A more personal stance garners more visibility, more citations and more professional credit. Something of this claim for recognition can be seen in these examples:

(25) From these data we have proposed a model for the distributive regulation of Byr2 by Rasl, Ste4, and Shkl.

(26) We suggest that some of these differences may be attributable to changes in the chromatin structure introduced by the fixation procedure itself.

(27) ...we are of the opinion that the first method (co-simulation by the simultaneous solution of the electrical and thermal problem) is superior, since it is applicable to a wider range of electro-thermal problems.

Personal reference is a clear indication of the perspective from which a statement should be interpreted, enabling writers to emphasize their own contribution and to seek agreement for it.

Sociology has followed a similar path with authors increasing their presence in their texts through self-mention, although this is perhaps more understandable than in the sciences. Here research is generally more explicitly interpretative and less abstract, with less 'exact' data collection proce- 
dures and less control of variables. Readers expect that authors will not write with positivist detachment but will craft a convincing argument using a credible stance:

(28) The political incorporation of women, we argue, is a worldwide process deeply influenced by world models of progress and justice and strongly associated with becoming a legitimate nation-state.

(Soc)

(29) I want to set out a different approach and suggest that this may be able to resolve some of the dualisms found in the previous contributions.

(Soc)

The patterns in applied linguistics, however, are more curious, with a substantial fall in self-mention over the last 50 years. This shift to a more faceless style of prose also underlines an increasing formality we have noticed in the research writing of this discipline (Authors, submitted). It possibly reflects an increase in empirically-oriented studies, as opposed to perhaps personalised accounts of teaching practices in earlier times, and where authors seek to moderate their personal stance to present research which can withstand the rigours of falsifiability. An alternative explanation may be the influence on the corpus of growing numbers of second language writers, most notably from China and the Middle East, schooled in the virtues of eliminating explicit agency from academic writing (e.g. Hyland, 2012). More likely, perhaps, is that it simply represents a heightened awareness, and growing selfconsciousness, among rhetorically-sensitive academics keen to replace an ego-centric stance with a more collectivist one.

These explanations, however, are rather fanciful, are their fragility is accentuated by the fact that both applied linguistics and sociology showed an increase in the use of singular first person over the period, with it doubling in the former since 1985 and increasing 3 fold in the latter. Quite clearly, the ability of authors to position themselves as reflective agents with important ideas to contribute (30) or insights to convey (31) remains very important in these fields:

(30) I raise the issue of forms of extreme social disadvantage and oppression which do not seem to stimulate a critical social scientific response. In this way, I am confronting fundamental issues of critical social science practice; I show why the experiences of very cognitively disabled people should be a central concern of critical sociologists, social historians and social theorists.

(Soc) 
(31) Whatever I decide to do with what I have learned about what originally puzzled me, I will also be aware of another type of knowledge which I take way from the research process. The research process will have taught me something about both of these aspects, in essence what has served my research needs and what has not. If the latter proves to be substantial then I will adopt a different approach as regards the techniques I choose the next time I do research.

While $I$ is increasing in the soft knowledge fields, we can see from Table 5 that we dominates the frequencies in all disciplines, comprising 58\% of all forms in 2015. This has nearly doubled in electrical engineering and increased by almost four times in biology, making it overwhelmingly the preferred marker of self-mention in the sciences. Clearly one reason for this is the growing trend, and career pressures, towards collaborative writing and co-authorship. Recent decades have seen the proportion of multi-authored papers gradually increase so, according to data from Thomson Reuters, the average number of authors on papers in the Science Citation Index grew by 50 percent between 1990 and 2010 (Hyland, 2015). Thus, while any issue of a journal such as Nature contains around the same number of articles today as one from 1950, it has about four times as many authors (Greene, 2013).

Today, collaboration and teamwork are among the most obvious features of scientific and technological research with a worldwide trend towards more co-authors affiliated to more universities in more countries. This development reflects both the publishing imperative of the performance culture and the growth of increasingly intricate multi-investigator research. Under career-defining review systems the world over, each author can claim each paper and each citation as his or her own, so creating a system which rewards heavily multi-authored papers. Co-authorship is also encouraged by the ever-growing complexity of the modern environment, and by extension, of research problems. Thus, almost half (46\%) of all UK authored articles in 2010, for example, were co-authored with a non-UK researcher, and this created a citation advantage greater than that of nationally authored or co-authored articles (Department of Business, Innovation and Skills, 2011). 
Multiple authorship is also growing in the soft disciplines, as can be seen by the increased use of we in our sociology corpus. There is a possibility that this reflects a trend towards studies aimed at, and funded by, a wider audience from the political, commercial and industrial worlds which prefer their research presented in a more objective fashion. Essentially, however, co-authorship creates research advantages as a result of sharing resources, ideas, expertise and data, as well as the synergistic creativity that comes from working with others. Perhaps more importantly, it also provides opportunities to effectively split the work to speed up progress and publish more articles, so that co-authorship is driven by the imperative of visibility and the fact that it enables academics to publish more, in higher impact journals and to collect more citations for their work.

\section{Final observations and conclusions}

In this paper we have tracked how the expression of authorial stance has changed in research writing over the past 50 years. Using Hyland's model and looking at the papers from leading journals in four representative disciplines, we have uncovered a somewhat surprising picture, finding that stance features have not kept pace with massive increases in the length of papers and that stance frequencies are increasing in the sciences and falling in the soft fields. These seem to be quite major, but largely unnoticed, recent historical changes which have resulted in a gradual movement towards rhetorical convergence as the hard and soft fields adjust their stance profiles to changing circumstances.

It appears that, from the point of view of authorial stance at least, we are witnessing slow changes in traditional knowledge construction practices. The cumulative and tightly structured procedures of the sciences have generally allowed for succinct communication and relatively "strong" claims which have been presented as emerging from observations in the lab rather than interpretations at the word processor. The relatively clear criteria for establishing or refuting claims has allowed authors to remove themselves from the picture, but research papers in both biology and electrical engineering, and particularly in the latter, display an increased deployment of stance markers, most noticeably self-mention. We speculate this may not be unrelated to the need to address audiences 
beyond an immediate group of informed insiders to promote both one's research and oneself with tenure and promotion committees and commercial sponsors.

In the more discursive fields we observe a marked trend in the opposite direction, towards less authorial intrusion and a less visible stance. Papers in the top applied linguistics and sociology journals contain far fewer hedges, boosters and attitude markers (per 10,000 words) than they did in 1965 and those in applied linguistics also contained less self-mention. These changes minimize authorial presence and convey more cautious stances, directing readers to the persuasive strength of data or methodological practice rather than the convictions of the interpreting writer.

Overall, our study supports research which shows an inexorable growth in formality and authorial withdrawal since the inception of scientific writing some 350 years ago, a change which Atkinson (1999) describes as a move from a less 'author-centred' rhetoric to a highly abstract and 'objectcentred one'. Using a cluster analysis of features, Atkinson found that papers steadily became less affectively and 'narratively' focused and more 'informational' and abstract over time, shifting from a discourse based around the experiencing gentleman-scientist to community generated research problems. Impersonalization is a powerful tool for repackaging research phenomena to downplay the interpreting researcher and 'semiotically reconstruct' (Halliday, 2004) experience to realise new ways of seeing the world. Just as the grammatical style of articles has emerged over the centuries from the political establishment of a scientific community, the changes we see in these stance choices similarly reflect changing audiences and material conditions. As Biber and Gray (2016) report in their study of academic research writing over the past two centuries, it appears that stance in academic writing is increasingly coming to be expressed implicitly rather than employing explicit grammatical devices.

It must be remembered, of course, that the stance an author takes, and the creation of an academic persona to which this stance contributes, is always an act of personal choice where the influence of personality, confidence, experience, and ideological preference are clearly important. Ultimately we are all rational agents rather than robotic instruments of our disciplines. However, writers do not act 
in a social vacuum and knowledge is not constructed outside particular communities of practice.

Such communities exist in virtue of a shared set of assumptions and routines about how to collectively deal with and represent their experiences. The ways language is used on particular occasions is not wholly determined by these assumptions, but a disciplinary voice can only be achieved through a process of participating in such communities and connecting with these socially determined and approved beliefs and value positions. In this way, independent creativity is shaped by accountability to shared practices. This is why disciplines do things differently and why the ways they do things change over time.

In the end, effective academic writing depends on rhetorical decisions about interpersonal intrusion which recognise and align with both disciplinary epistemologies and social practices and with wider political and institutional changes. The most significant of these in recent times would seem to concern the ways knowledge is constructed and disseminated to new audiences outside a traditional peer group, including commercial and industrial sponsors who might make use of the knowledge created and personnel boards who make high stakes decisions regarding the careers of academic writers.

\section{References}

Anthony, L. (2011). AntConc 3.4.3. http://www.laurenceanthony.net/software.html

Atkinson, D. (1999). Scientific discourse in sociohistorical context: The philosophical transactions of the Royal Society of London, 1675-1975. Mahwah, NJ: Lawrence Erlbaum.

Aull, L. L., \& Lancaster, Z. (2014). Linguistic markers of stance in early and advanced academic writing a corpus-based comparison. Written Communication, 31, 151-183.

Bazerman, C. (1984). Modern evolution of the experimental report in physics: Spectroscopic articles in Physical Review, 1893-1980. Social studies of science, 14(2), 163-196.

Besnier, N. (1990) 'Language and affect', Annual Review of Anthropology, 19, 419-451.

Biber, D. (2006) University language: a corpus-based study of spoken and written registers (Amsterdam: John Benjamins).

Biber, D. and Finegan, E. (1989). Styles of stance in English: lexical and grammatical marking of evidentiality and affect. Text. 9 (1), 93-124. 
Biber, D., \& Gray, B. (2016). Grammatical complexity in academic English: Linguistic change in writing. Cambridge: Cambridge University Press.

Biber, D., Johansson, S., Leech, G., Conrad, S., \& Finegan, E. (1999). Longman grammar of spoken and written English. Harlow: Longman.

Chafe, W. (1986) 'Evidentiality in English conversation and academic writing in Chafe, W. and J. Nichols (eds.) Evidentiality: the linguistic coding of epistemology. Norwood, NJ: Ablex.

Chafe, W. and J. Nichols (1986) Evidentiality: the linguistic coding of epistemology. Norwood, NJ: Ablex.

Charles, M. (2006) 'The construction of stance in reporting clauses: a cross-disciplinary study of theses', Applied Linguistics, 27, 492-518.

Department of Business, Innovation and Skills. (2011). International Comparative Performance of the UK Research Base - 2011. London: Elsevier.

Dressen, D. (2003) 'Geologists' implicit persuasive strategies and the construction of evaluative evidence', Journal of English for Academic Purposes, 2, 273-290.

Geertz, C. (1988) Works and Lives: The Anthropologist as Author. Stanford: Stanford University Press.

Grabe, W. (1984) Towards defining expository prose within a theory of text construction, Unpublished doctoral dissertation (Los Angeles: University of Southern California).

Gray, B. \& Biber, D. (2012). Current conceptions of stance. In Hyland, K. \& Sancho-Guinda, C. (Eds.) Stance and voice in written academic genres. London: Palgrave: 15-33.

Greene, M. (2013). History of the journal Nature. doi:10.1038/nature06243

Halliday, MAK (2004). The Language of Science. J. Webster (ed.). $5^{\text {th }}$ volume of a of the Collected Works of M.A.K. Halliday. London/ New York: Continuum

Hood, S. (2010), Appraising Research: Evaluation in Academic Writing. London: Palgrave.

Hundt, M. \& Mair, C. (1999). "Agile" and "Uptight" Genres: The Corpus-based Approach to Language Change in Progress. International Journal of Corpus Linguistics. 4:2: 221-242

Hunston, S. (1994). Evaluation and organisation in a sample of written academic discourse. In M. Coulthard. (ed.) Advances in written text analysis. (pp. 191-218). London: Routledge

Hunston, S., \& Thompson, G. (Eds.). (2000). Evaluation in text . Oxford: OUP.

Hyland, K. (1998). Hedging in scientific research articles. Amsterdam: John Benjamins. 
Hyland, K. (1999) 'Disciplinary discourses: writer stance in research articles' in Candlin, C. and K. Hyland (eds.) Writing: texts, processes and practices (London: Longman).

Hyland, K. (2004) Disciplinary discourses (Ann Arbor: University of Michigan).

Hyland (2005a). Metadiscourse. London: Continuum.

Hyland, K. (2005b) ‘Stance and engagement: a model of interaction in academic discourse’, Discourse Studies, 7, 1461-4456.

Hyland, K. (2012) Disciplinary identities (Cambridge: CUP).

Hyland, K. (2015). Academic publishing: issues and challenges in the construction of knowledge. Oxford: OUP.

Hyland, K. and P. Tse (2005) 'Hooking the reader: a corpus study of evaluative that in abstracts', English for Specific Purposes, 24, 123-139.

Ivanic, R. (1998). Writing and Identity: The discoursal construction of identity in academic writing. Amsterdam: Benjamins.

Labov, W. (1984) 'Intensity' in D. Schiffrin (ed.) Meaning, form and use in context: linguistic applications (Washington: Georgetown University Press).

Lancaster, Z. (2014). Exploring valued patterns of stance in upper-level student writing in the disciplines. Written Communication, 31, 27-57.

Martin, J.R. (2000) ‘Beyond exchange: APPRAISAL systems in English’ in Hunston, S. and G. Thompson (eds) Evaluation in text (Oxford: Oxford University Press).

Martin, J.R. and P.R.R. White (2005) The language of evaluation: appraisal in English (Houndmills, Basingstoke, UK: Palgrave Macmillan).

Ochs, E. and B. Schieffelin (1989) 'Language has a heart', Text, 9, 7-25.

Palmer, F.R. (1986) Mood and modality (Cambridge: Cambridge University Press).

Quirk, R., S. Greenbaum, G. Leech and J. Svartvik (1985) A comprehensive grammar of the English language (London: Longman).

Seone, E. (2013). On the conventionalisation and loss of pragmatic function of the passive in Late Modern English scientific discourse. Journal of Historical Pragmatics 14 (1), 70-99

Tucker, P. (2003) 'Evaluation in the art-historical research article', Journal of English for Academic Purposes, 2, 291-312. 
Uccelli, P., Dobbs, C. L., \& Scott, J. (2013). Mastering academic language organization and stance in the persuasive writing of high school students. Written Communication, 30, $36-62$. 
Appendix 1: Journal list

Applied Linguistics

TESOL Quarterly (1967- )

Language Learning (1948- )

Foreign Language Annals (1967- )

Modern Language Journal (1916- )

College Composition and Communication (1950- )

\section{Sociology}

American Journal of Sociology (1895- )

Social problems (1953- )

The British Journal of Sociology (1950- )

American Journal of Economics and Sociology (1941- )

The Sociological Quarterly (1960- )

\section{Biology}

The Quarterly Review of Biology (1926- )

Biological Reviews (1923- )

Radiation Research (1954- )

BioScience (1964- )

The Journal of Experimental Biology (1923 - )

\section{Eletronic Engineering}

Proceedings of the IEEE (1963 - )

Automatica (1963 - )

IEEE Transactions on Automatic Control (1963 - )

IEEE Journal of Solid-State Circuits (1966 - )

IEEE Transactions on Information Theory (1963 - ) 